\title{
The Association between Transcatheter Aortic Valve Replacement (TAVR) Approach and New-Onset Bundle Branch Blocks
}

\author{
Ali M. Agha (1) · Jeremy R. Burt · Danielle Beetler · Tri Tran · \\ Ryan Parente $\cdot$ William Sensakovic $\cdot$ Yuan Du $\cdot$ Usman Siddiqui
}

Received: April 15, 2019 / Published online: May 23, 2019

(C) The Author(s) 2019

\begin{abstract}
Introduction: Transcatheter aortic valve replacement (TAVR) has become a widely accepted treatment option for patients with severe aortic stenosis (AS) who are considered intermediate- and high-risk surgical candidates. The purpose of this study was to test the hypothesis that trans-apical TAVR would be associated with increased risk of new-onset intraventricular conduction delay (LBBB or RBBB).
\end{abstract}

Methods: We conducted a retrospective observational study of consecutive patients

Enhanced digital features To view enhanced digital features for this article go to https://doi.org/10.6084/ m9.figshare.8094509.

A. M. Agha $(\bowtie)$

Department of Internal Medicine, The McGovern Medical School at UT Houston, Houston, TX, USA e-mail: ali.m.agha@uth.tmc.edu

J. R. Burt · D. Beetler · T. Tran · R. Parente .

W. Sensakovic

Department of Radiology, AdventHealth Orlando, Orlando, FL, USA

Y. Du

AdventHealth Orlando, Translational Research, Institute, Orlando, FL, USA

U. Siddiqui

Department of Cardiology, AdventHealth Orlando, Orlando, FL, USA undergoing TAVR at a large, single institution. The incidence of new LBBB or RBBB was compared between femoral and apical TAVR patients. Multivariate analysis was performed to account for confounding variables, which included age, gender, CAD, PAD, hypertension, and diabetes.

Results: A total of 467 TAVR patients were included in the study, with 283 (60.6\%) femoral approach and 184 (39.4\%) apical approach. In univariate analysis, the apical approach (when compared to the femoral approach) was associated with a higher incidence of both new-onset LBBB (12.79 vs. $3.40 \%, p=0.0002$ ) and RBBB (5.49 vs. $0.81 \%, p=0.0039$ ). After controlling for potential confounding variables, the apical approach continued to be associated with a higher incidence of both new-onset LBBB $(p=0.0010)$ and RBBB $(p=0.0115)$. There was also a trend towards an association between diabetes and new-onset LBBB $(p=0.0513)$ in apical TAVR patients. In subgroup analysis, $\mathrm{LBBB} / \mathrm{RBBB}$ occurring as a result of transapical TAVR was associated with more frequent hospitalizations $>30$ days after TAVR, compared to transfemoral TAVR. Other post-procedural complications noted more frequently among patients undergoing transapical TAVR include arrhythmias including atrial fibrillation, periprocedural myocardial infarction (within $72 \mathrm{~h}$ ), mortality from unknown cause, and mortality from non-cardiac cause. 
Conclusions: Relative to transfemoral TAVR, patients undergoing transapical TAVR are at increased risk for new-onset bundle branch block, peri-procedural myocardial infarction, rehospitalization, TAV-in-TAV deployment, and all-cause mortality at 1 year. Interventional cardiologists and cardiothoracic surgeons alike should take these findings into consideration when choosing which approach is most suitable for patients undergoing TAVR for severe aortic stenosis.

Keywords: Intraventricular conduction delays; Left bundle branch block; Right bundle branch block; Transcatheter aortic valve replacement

\section{INTRODUCTION}

Transcatheter aortic valve replacement (TAVR) has become a widely accepted treatment option for patients with severe aortic stenosis (AS) who are considered intermediate- and high-risk surgical candidates. However, TAVR is not without potential complications; one of the most common being new onset of intraventricular conduction delay [i.e., left bundle branch block (LBBB) or right bundle branch block (RBBB)] [1]. The clinical impact of these intraventricular conduction delays is controversial. Of note, a 2016 meta-analysis demonstrated that new-onset LBBB after TAVR was associated with increased mortality and permanent pacemaker (PPM) implantation at 1 year [2]. Baseline RBBB has been associated with poorer clinical outcomes (such as increased mortality) after TAVR [3], although the impact of new-onset RBBB after TAVR is not well known. The purpose of this study was to test the hypothesis that transapical TAVR would be associated with increased risk of new-onset intraventricular conduction delay (LBBB or RBBB).

\section{METHODS}

We performed a retrospective, observational study of consecutive patients undergoing TAVR between January 1, 2012 and February 15, 2018, which was approved by the Florida Hospital Institutional Review Board (IRB) prior to data collection, which conformed with the Helsinki Declaration of 1964, as revised in 2013, concerning human and animal rights. Informed consent was obtained by the patients for being included in the study.

A total of 23 patients with previously identified LBBB/RBBB/PPM, lack of medical, surgical, and/or demographic information, and those who were not between 18 and 90 years old were excluded. The incidence of new LBBB or RBBB, in addition to demographic information, was recorded. All TAVR patients meeting inclusion criteria had telemetry monitoring for at least $24 \mathrm{~h}$ following the procedure.

The incidence of new LBBB or RBBB was determined between femoral and apical TAVR patients using the Chi-square test or Fischer's exact test of independence. Multivariate analysis was performed to account for confounding variables, which included age, gender, CAD, PAD, hypertension, and diabetes. All tests were two-tailed and a value of 0.05 was selected for statistical significance. No $p$ value adjustment was made for multiple tests conducted. Statistical analysis was performed with SAS 9.4 (SAS Institute, Cary, NC, USA).

\section{RESULTS}

A total of 489 TAVR patients were included in the study, with 302 (62\%) femoral approach and 187 (38\%) apical approach. With respect to demographics, the two groups were well matched, except those undergoing transapical TAVR had a higher incidence of peripheral arterial disease (PAD) and smoking history (Table 1).

Pre-procedurally, the two groups were similar, except those undergoing transfemoral TAVR more often had prior PPM and moderate/severe left ventricular outflow tract (LVOT) calcification (Table 2). Intra-procedurally, those undergoing transapical TAVR more frequently demonstrated malposition of the prosthesis 
Table 1 Summary demographics

\begin{tabular}{|c|c|c|c|}
\hline & Transfemoral & Transapical & $p$ value \\
\hline Approach & $302(62)$ & $187(38)$ & \\
\hline Age, years, median (range) & $81 \pm 8.9(46-96)$ & $82 \pm 8(41-99)$ & 0.12 \\
\hline Male & $171(57)$ & $112(60)$ & 0.48 \\
\hline Race/ethnicity & & & 0.7 \\
\hline Nonhispanic white & $268(89)$ & $161(86)$ & \\
\hline Nonhispanic black & $6(2)$ & $4(2)$ & \\
\hline Hispanic & $18(6)$ & $15(8)$ & \\
\hline Asian & $3(1)$ & $4(2)$ & \\
\hline Other & $7(2)$ & $3(2)$ & \\
\hline CAD & $226(75)$ & $152(81)$ & 0.11 \\
\hline Hypertension & $284(94)$ & $175(94)$ & 0.73 \\
\hline Pulmonary hypertension & $42(14)$ & $19(10)$ & 0.22 \\
\hline Diabetes & $111(37)$ & $62(33)$ & 0.39 \\
\hline BMI, $n$, mean & $28.3 \pm 9.8$ & $28.5 \pm 15.8$ & ns \\
\hline Obesity & $92(31)$ & $54(29)$ & 0.67 \\
\hline Chronic liver disease & $8(3)$ & $3(2)$ & 0.45 \\
\hline Non-aortic valve disease & $220(73)$ & $145(77)$ & 0.27 \\
\hline Bicuspid aortic valve & $9(3)$ & $5(3)$ & 0.77 \\
\hline Congenital heart disease & $16(5)$ & $0(0)$ & $0.0013^{*}$ \\
\hline CVA & $39(13)$ & $23(12)$ & 0.83 \\
\hline PAD & $67(22)$ & $83(44)$ & $<0.0001^{*}$ \\
\hline Smoking (current or prior) & $151(51)$ & $114(62)$ & $0.0162^{*}$ \\
\hline
\end{tabular}

Data are numbers of participants, with percentages in parentheses

$B M I$ body mass index, $C A D$ coronary artery disease, $C V A$ stroke, $P A D$ peripheral artery disease

${ }^{*}$ Statistically significant

(including low implantation depth) or required subsequent TAV-in-TAV deployment (Table 3).

In univariate analysis, the apical approach (when compared to the femoral approach) was associated with a higher incidence of both new onset LBBB (12.79 vs. 3.40\%, $p=0.00007)$ and RBBB (5.49 vs. $1.5 \%, p=0.01$ ) (Fig. 1). After controlling for potential confounding variables, the apical approach continued to be associated with a higher incidence of both new onset LBBB 
Table 2 Preprocedural characteristics

\begin{tabular}{lccc}
\hline & Transfemoral & Transapical & $\boldsymbol{p}$ value \\
\hline $\begin{array}{l}\text { Permanent } \\
\text { pacemaker }\end{array}$ & $19(6)$ & $3(2)$ & $0.014^{*}$ \\
Prior IVCD & $57(19)$ & $30(16)$ & 0.43 \\
RBBB & $37(12)$ & $22(7)$ & 0.87 \\
LBBB & $20(11)$ & $8(4)$ & 0.28 \\
$\begin{array}{l}\text { Degree of AV } \\
\text { calcification }\end{array}$ & & & 0.3 \\
$\begin{array}{l}\text { Minimal } \\
\text { Mild }\end{array}$ & $5(2)$ & $1(1)$ & \\
Moderate & $110(39)$ & $59(35)$ & \\
$\begin{array}{l}\text { Severe } \\
\text { Moderate or }\end{array}$ & $22(8)$ & $3(2)$ & $0.0001^{*}$ \\
severe LVOT & & & \\
calcification & & $57(58)$ & \\
$\begin{array}{l}\text { Tortuous iliac } \\
\text { arteries }\end{array}$ & $116(41)$ & $54(32)$ & 0.28 \\
\hline
\end{tabular}

Data are numbers of participants, with percentages in parentheses

$I V C D$ intraventricular conduction delay, $R B B B$ right bundle branch block, $L B B B$ left bundle branch block, $A V$ aortic valve, $L V O T$ left ventricular outflow tract ${ }^{*}$ Statistical significance

$(p=0.001)$ and RBBB $(p=0.01)$ (Table 4$)$. There was also a trend towards an association between diabetes and new-onset LBBB $(p=0.0513)$ in transapical TAVR patients.

In subgroup analysis, LBBB/RBBB occurring as a result of transapical TAVR was associated with more frequent hospitalizations $>30$ days after TAVR, compared to transfemoral TAVR (Table 5).

Other post-procedural complications noted more frequently among patients undergoing
Table 3 Intraprocedural outcomes

\begin{tabular}{|c|c|c|c|}
\hline & Transfemoral & Transapical & $p$ value \\
\hline $\begin{array}{l}\text { Malposition of } \\
\text { bioprosthesis } \\
\text { including low } \\
\text { implantation } \\
\text { depth** }\end{array}$ & $13(4)$ & $18(10)$ & $0.02^{*}$ \\
\hline $\begin{array}{l}\text { Unplanned use of } \\
\text { cardiopulmonary } \\
\text { bypass }\end{array}$ & $1(0.5)$ & $1(0.3)$ & 0.73 \\
\hline $\begin{array}{l}\text { Conversion to } \\
\text { open surgery }\end{array}$ & $3(1)$ & $1(0.5)$ & 0.58 \\
\hline $\begin{array}{l}\text { TAV-in-TAV } \\
\text { deployment }\end{array}$ & $13(4)$ & $18(10)$ & $0.02^{*}$ \\
\hline Aortic rupture & $1(0.3)$ & $0(0)$ & 0.62 \\
\hline Aortic dissection & $0(0)$ & $0(0)$ & \\
\hline $\begin{array}{l}\text { Ventricular septal } \\
\text { perforation }\end{array}$ & $0(0)$ & $2(1)$ & 0.15 \\
\hline $\begin{array}{l}\text { Acute severe aortic } \\
\text { regurgitation }\end{array}$ & $0(0)$ & $1(0.3)$ & 0.62 \\
\hline $\begin{array}{l}\text { Mitral valve } \\
\text { damage }\end{array}$ & $0(0)$ & $0(0)$ & \\
\hline $\begin{array}{l}\text { Guidewire related } \\
\text { trauma }\end{array}$ & $4(1)$ & $1(0.5)$ & 0.65 \\
\hline Major bleeding & $8(3)$ & $9(5)$ & 0.2 \\
\hline Mortality & $0(0)$ & $1(0.5)$ & 0.38 \\
\hline
\end{tabular}

Data are numbers of participants, with percentages in parentheses

$T A V$ transcatheter aortic valve

${ }^{*}$ Statistical significance

** Depth of intraventricular end of bioprosthesis $>6 \mathrm{~mm}$ below annulus is considered low

transapical TAVR include arrhythmias including atrial fibrillation, peri-procedural myocardial infarction (within $72 \mathrm{~h}$ ), mortality from unknown cause, and mortality from non-cardiac cause (Table 6). 


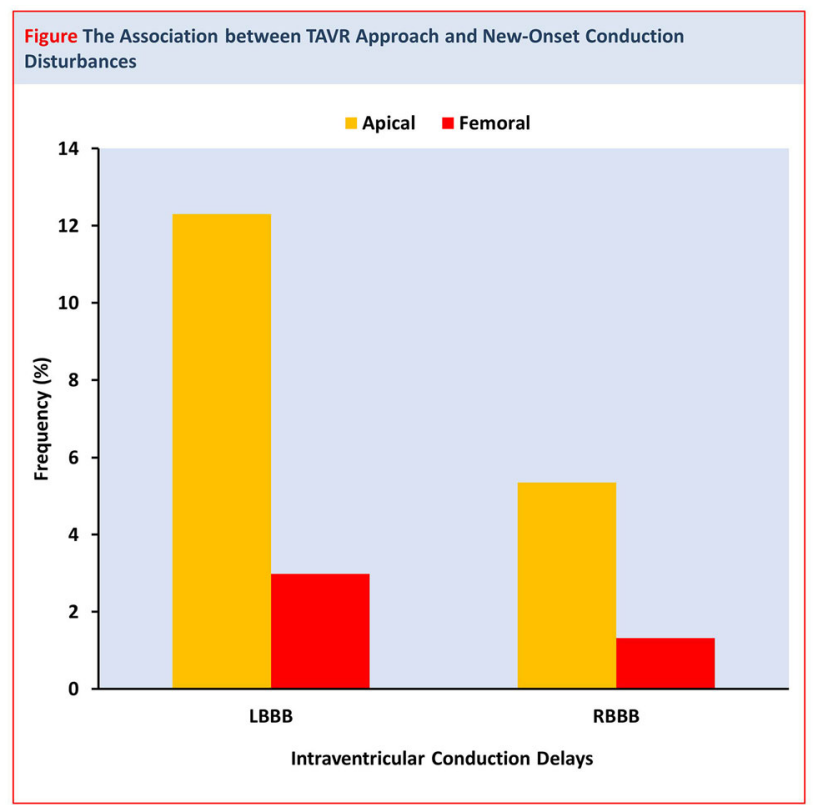

Fig. 1 The apical approach (when compared to the femoral approach) was associated with a higher incidence of both new onset $\mathrm{LBBB}$ and RBBB

Table 4 Logistic regression analyses

\begin{tabular}{lll}
\hline & Odds ratio & $p$ value \\
\hline LBBB $^{\mathrm{a}}$ & $3.85(1.72,9.09)$ & 0.001 \\
$\mathrm{RBBB}^{\mathrm{a}}$ & $7.69(1.56,33.3)$ & 0.0115 \\
Periprocedural MI $(\leq 72 \mathrm{~h})$ & $3.85(1.43,10)$ & 0.008 \\
Prosthesis malposition & $2.78(0.9,8.3)$ & 0.08 \\
TAV-in-TAV deployment & $2.44(1.15,5.26)$ & 0.02 \\
$\begin{array}{l}\text { Death from unknown } \\
\text { causes (12-month follow- } \\
\text { up) }\end{array}$ & $7.69(0.91,100)$ & 0.06 \\
$\begin{array}{l}\text { Death from non-cardiac } \\
\text { causes (12-month follow- }\end{array}$ & & \\
up) & & \\
\hline
\end{tabular}

Data are odds ratios with $95 \%$ confidence intervals in parentheses

Logistic regression models were fit for TAVR approach (transfemoral vs. transapical), adjusting for age, gender, CAD, PAD, hypertension, and diabetes; limited to examinations with nonmissing covariates

$M I$ myocardial infarction, $T A V$ transcatheter aortic valve

${ }^{a} \mathrm{LBBB}$ and $\mathrm{RBBB}$ subgroups analyzed after excluding patients with history of bundle branch block prior to TAVR

\section{DISCUSSION}

We found an increased incidence of new-onset BBB in patients undergoing transapical TAVR compared with transfemoral TAVR. Our findings correlate well with those of other TAVR studies [4-6]. The incidence of new-onset LBBB has been more exhaustively analyzed than newonset RBBB, presumably due to more concerning clinical implications of new-onset LBBB. Published incidence rates of LBBB range from 4 to $65 \%$ with first-generation valves and $18-65 \%$ with balloon-expandable valves [1].

Other clinical risk factors that predict newonset LBBB after TAVR include female gender, previous coronary artery bypass graft (CABG), pre-procedural QRS prolongation, diabetes mellitus, and prosthesis implantation depth within the LVOT, which is the most consistently reported predictor of intraventricular conduction delays [1]. We found an increased percentage of transapical TAVR patients in our study with low implantation depth, which may help to explain the increased risk of new-onset BBB in this group. Correspondingly, the transapical group was also at increased risk for 
Table 5 Outcomes by type of IVCD*

\begin{tabular}{llll}
\hline & Transfemoral & Transapical & $\boldsymbol{p}$ value \\
\hline New RBBB $(n=14)$ & & & \\
Patients, $n$ (after excluding prior RBBB) & 265 & 165 & \\
Permanent pacemaker & $0(0)$ & $2(1)$ & 0.15 \\
Cardiac resynchronization treatment (CRT) & $0(0)$ & $0(0)$ & \\
All-cause rehospitalization $<30$ days after TAVR & $1(0.4)$ & $2(1)$ & 0.3 \\
Rehospitalization for TAVR complication $<30$ days after TAVR & $1(0.4)$ & $2(1)$ & 0.3 \\
All-cause hospitalization $\geq 30$ days after TAVR & $0(0)$ & $6(4)$ & $0.003^{* *}$ \\
Hospitalization for MACE $\geq 30$ days after TAVR & $0(0)$ & $4(2)$ & $0.02^{* *}$ \\
Death $<30$ days after TAVR & $1(0.4)^{\mathrm{a}}$ & $1(0.6)^{\mathrm{b}}$ & 0.7 \\
Death $\geq 30$ days to $<1$ year after TAVR & $0(0)$ & $1(0.6)^{\mathrm{c}}$ & 0.38 \\
New LBBB $(n=32)$ & & & \\
Patients, $n$ (after excluding prior LBBB) & 282 & 179 & $1(0.5)$ \\
Permanent pacemaker & $3(1)$ & $0(0)$ & 0.57 \\
Cardiac resynchronization treatment $($ CRT) & $0(0)$ & $1(0.5)$ & 0.84 \\
All-cause rehospitalization $<30$ days after TAVR & $2(0.7)$ & $1(0.5)$ & 0.74 \\
Rehospitalization for TAVR complication $<30$ days after TAVR & $1(0.3)$ & $10(6)$ & $0.01^{* *}$ \\
All-cause hospitalization $\geq 30$ days after TAVR & $4(1)$ & $7(4)$ & 0.09 \\
Cardiac hospitalization $\geq 30$ days after TAVR & $4(1)$ & $0(0)$ & \\
Death $<30$ days after TAVR & $0(0)$ & $1(0.5)^{\mathrm{d}}$ & 0.39 \\
Death $\geq 30$ days to $<1$ year after TAVR & $0(0)$ & & \\
\hline
\end{tabular}

IVCD intraventricular conduction delay, MACE major adverse cardiovascular event (admission for heart failure, ischemic cardiovascular events, cardiac death, stroke)

${ }^{*}$ Data are numbers of participants, with percentages in parentheses

${ }^{* *}$ Statistically significant

${ }^{a}$ Ventricular fibrillation with cardiac arrest during TAVR

b Heart failure

${ }^{c}$ Heart failure

${ }^{\mathrm{d}}$ Uknown cause

needing TAV-in-TAV deployment to correct prosthesis malposition.

Our study also demonstrated a trend towards diabetes as an independent risk factor for newonset LBBB in transapical TAVR patients. This is particularly concerning, as patients with LBBB and diabetes demonstrate more severe left ventricular systolic dysfunction than those with LBBB but without diabetes [7].
Overall, intra-procedural and post-procedural morbidity and mortality were also increased in the transapical group. This included increased risk for arrhythmias, peri-procedural MI, readmission, and all-cause mortality. We also witnessed a trend towards increased risk of acute kidney injury and significant post-procedural hemorrhage in the transapical group. These findings correspond with a recent 
Table 6 Postprocedural outcomes (within 30 days unless otherwise indicated)

\begin{tabular}{|c|c|c|c|}
\hline & Transfemoral & Transapical & $p$ value \\
\hline $\begin{array}{l}\text { Conduction } \\
\text { disturbances/ } \\
\text { arrhythmias }\end{array}$ & $136(45)$ & $117(63)$ & $0.0002^{*}$ \\
\hline $\mathrm{RBBB}$ & $4(1.5)$ & $10(5.5)$ & $0.01^{*}$ \\
\hline LBBB & $9(3)$ & $23(13)$ & $0.00007^{*}$ \\
\hline $\begin{array}{l}\text { Paravalvular } \\
\text { leak }(\leq 72 \mathrm{~h})\end{array}$ & $70(23)$ & $50(27)$ & 0.38 \\
\hline CVA/TIA & $3(1)$ & $3(2)$ & 0.68 \\
\hline $\begin{array}{l}\text { Periprocedural } \\
\qquad \mathrm{MI}(\leq 72 \mathrm{~h})\end{array}$ & $6(2)$ & $13(7)$ & $0.006^{*}$ \\
\hline $\begin{array}{l}\text { Myocardial } \\
\text { infarction } \\
(>72 \mathrm{~h})\end{array}$ & $2(0.7)$ & $0(0)$ & 0.53 \\
\hline $\begin{array}{l}\text { 1-year mortality } \\
\text { due to cardiac } \\
\text { cause }\end{array}$ & $2(0.7)$ & $2(1)$ & 0.63 \\
\hline $\begin{array}{l}\text { 1-year mortality } \\
\text { due to non- } \\
\text { cardiac cause }\end{array}$ & $2(0.7)$ & $8(4)$ & $0.008^{*}$ \\
\hline $\begin{array}{l}\text { 1-year mortality } \\
\text { due to } \\
\text { unknown } \\
\text { cause }\end{array}$ & $1(0.3)$ & $5(3)$ & $0.02^{*}$ \\
\hline $\begin{array}{l}\text { Valve-related } \\
\text { death }\end{array}$ & $0(0)$ & $1(0.5)$ & 0.38 \\
\hline $\begin{array}{l}\text { Valve } \\
\text { thrombosis }\end{array}$ & $0(0)$ & $1(0.5)$ & 0.38 \\
\hline $\begin{array}{l}\text { Acute kidney } \\
\text { injury }\end{array}$ & $13(4)$ & $13(7)$ & 0.2 \\
\hline Bleeding & $12(4)$ & $13(7)$ & 0.15 \\
\hline Endocarditis & $0(0)$ & $0(0)$ & \\
\hline
\end{tabular}

Data are numbers of participants, with percentages in parentheses

$R B B B$ right bundle branch block, $L B B B$ left bundle branch block, CVA/TIA cerebrovascular accident/transient ischemic attack

${ }^{*}$ Statistically significant publication by Stamou et al. who reported increased risk of blood transfusions, readmission, postoperative stroke, and atrial fibrillation in patients undergoing alternative access (nonfemoral) TAVR [4]. Others have also noticed a trend towards improved 1-year survival rates in the transfemoral TAVR patients relative to the transapical approach [5].

Study limitations: this study was nonrandomized, with results that may be influenced by unmeasured confounders. The small number of certain outcomes, such as mortality, precludes a more detailed statistical analysis to evaluate for underlying confounding variables. This study was not designed to specifically evaluate mortality in transfemoral vs. transapical TAVR patients according to VARC- 2 consensus guidelines [6] and we encourage future investigators to add to the body of literature in this regard. Data regarding specific valve type were not recorded. Also, data regarding the use of various atrioventricular node-blocking medications and electrocardiographic findings in our patients was not available.

\section{CONCLUSIONS}

Relative to transfemoral TAVR, patients undergoing transapical TAVR are at increased risk for new-onset bundle branch block, peri-procedural myocardial infarction, rehospitalization, TAVin-TAV deployment, and all-cause mortality at 1 year. Interventional cardiologists and cardiothoracic surgeons alike should take these findings into consideration when choosing which approach is most suitable for patients undergoing TAVR for severe aortic stenosis.

\section{ACKNOWLEDGEMENTS}

Funding. No funding or sponsorship was received for this study or publication of this article. The article processing charges were funded by the authors.

Authorship. All named authors meet the International Committee of Medical Journal 
Editors (ICMJE) criteria for authorship for this article, take responsibility for the integrity of the work as a whole, and have given their approval for this version to be published.

Disclosures. Ali M. Agha, Jeremy R. Burt, Danielle Beetler, Tri Tran, Ryan Parente, William Sensakovic, Yuan Du, and Usman Siddiqui have nothing to disclose.

Compliance with Ethics Guidelines. We received the approval of the Florida Hospital institutional review board prior to initiating this study, which conformed to the Helsinki Declaration of 1964 , as revised in 2013, concerning human and animal rights. Informed consent was obtained by the patients for being included in the study.

Data Availability. The datasets generated during and/or analyzed during the current study are available from the corresponding author on reasonable request. We thank the participants of the study.

Open Access. This article is distributed under the terms of the Creative Commons Attribution-NonCommercial 4.0 International License (http://creativecommons.org/licenses/ by-nc/4.0/), which permits any noncommercial use, distribution, and reproduction in any medium, provided you give appropriate credit to the original author(s) and the source, provide a link to the Creative Commons license, and indicate if changes were made.

\section{REFERENCES}

1. Auffret V, et al. Conduction disturbances after transcatheter aortic valve replacement: current status and future perspectives. Circulation. 2017;136(11): 1049-69.

2. Regueiro A, et al. Impact of new-onset left bundle branch block and periprocedural permanent pacemaker implantation on clinical outcomes in patients undergoing transcatheter aortic valve replacement: a systematic review and meta-analysis. Circ Cardiovasc Interv. 2016;9(5):e003635.

3. Auffret V, et al. Clinical impact of baseline right bundle branch block in patients undergoing transcatheter aortic valve replacement. JACC Cardiovasc Interv. 2017;10(15):1564-74.

4. Stamou SC et al. Alternative access versus transfemoral transcatheter aortic valve replacement in nonagenarians. J Invasive Cardiol. 2019 (Epublication ahead of print).

5. Arai $\mathrm{T}$, et al. Direct comparison of feasibility and safety of transfemoral versus transaortic versus transapical transcatheter aortic valve replacement. JACC Cardiovasc Interv. 2016;9(22):2320-5.

6. Kappetein $\mathrm{AP}$, et al. Updated standardized endpoint definitions for transcatheter aortic valve implantation: the Valve Academic Research Consortium-2 consensus document. J Am Coll Cardiol. 2012;60(15):1438-54.

7. Guzman E, et al. Left bundle branch block in type 2 diabetes mellitus: a sign of advanced cardiovascular involvement. Ann Noninvasive Electrocardiol. 2004;9(4):362-5. 